\title{
La mujer trae armonía: una aproximación a las representaciones de los roles de la mujer a través de los sellos postales chilenos (1964-1995)
}

\author{
Woman brings harmony: \\ an approach to the representation of the roles of women \\ through Chilean postage stamps (1964-1995) \\ Elena Romero Pérez \\ Escuela de Educación en Historia y Geografía \\ Universidad Católica Silva Henríquez-Chile \\ eromero@ucsh.cl
}

\section{Resumen}

El artículo estudia los sellos postales emitidos en Chile entre 1964 y 1995, para lo que se realizó un catastro de 779 estampillas en las que se establecieron categorías de análisis para poder identificar los roles de género presentes en esta fuente. El trabajo plantea como hipótesis el que en los sellos postales emitidos en Chile entre 1964 - 1995, las representaciones y roles asignados a las mujeres se vincularon a roles tradicionales como el de madre y pilar de la familia, donde, además, la influencia católica se hace presente a través de la imagen de ejemplos de virtud como la Virgen María, santas y beatas. Esto se produce durante todo el período, independiente de la ideología del gobierno de turno. En concordancia, el objetivo general es indagar en los roles de género asignados a las mujeres en representaciones y textos de los sellos postales emitidos en Chile en el período señalado.

Al haber pocos estudios que aborden la temática con esta fuente, el estudio es de carácter cualitativo, exploratorio y descriptivo.

Palabras clave: Sellos postales, representaciones y roles de género, propaganda.

\begin{abstract}
The article studies the postage stamps issued in Chile between 1964 - 1995, for which a registry of 779 stamps was carried out, in which analysis categories were established to identify the gender roles present in this source. The work hypothesizes that in the postage stamps issued in Chile between 1964 - 1995, the representations and roles assigned to woman are linked to traditional roles such as mother and pillar of the family. In addition, the Catholic influence is makes present through the image of examples of virtue such as the Virgin Mary, saints an blesses women. This occurs throughout the period, regardless of the ideology of the government in power. Accordingly,
\end{abstract}


the general objective is to investigate the gender roles assigned to women in representations and text of the postage stamps. As there few studies that address the issue with this source, the study is qualitative, exploratory, and descriptive.

Keywords: Postal stamps, gender roles and representations, propaganda.

Recibido: 05 de mayo 2021 - Aceptado: 23 de julio de 2021

\section{Introducción y contextualización}

El sello postal nos remite a un mundo anterior al auge de internet, momento en que uno de los principales medios de comunicación eran las cartas, donde, en lo local, Correos de Chile jugaba un rol fundamental puesto que:

[...] a fines de la década de los 90 la actividad postal representaba casi la totalidad de las ventas, al año 2015 ya representaba el $66 \%$ de los ingresos con un total de 10.4 millones de envíos durante el año... Sin embargo, la participación de mercado de la empresa en el mercado postal (cartas) ha estado disminuyendo durante los últimos años, pues si al año 2008 contaba con una participación cercana al $80 \%$, hoy en día no cuentan con más del 65 \%... (Asain, 2017: 2).

No obstante, la Casa de Moneda continúa emitiendo sellos postales: según la unidad de abonados filatélicos de Correos de Chile durante 2019 se emitieron ocho estampillas, mientras que en 2020 fueron cinco los sellos publicados. Debemos recordar que las estampillas: "son una forma de comunicación y de cultura. Ellos llevan un mensaje propio y conducen a la comprensión del mundo" (Child, 2008: 12). Dicho mensaje no es azaroso, dado que al ser planificados, diseñados y emitidos por una entidad estatal que los monopoliza, los convierte en producto de la ideología de cada gobierno de turno:

Por tanto, la ideología de un Estado, cualquiera que sea, es discernible a través de su producción postal, pues en los valores filatélicos pueden hallarse mensajes emitidos desde el gobierno cuyo receptor es tanto la propia ciudadanía como la ajena, la de otros países (Navarro, 2015: 14).

No está de más recordar que el valor de los sellos no solo es patrimonial, sino que también es monetario, ya que cada estampilla tiene impreso el precio por el que circuló en su época. De allí la importancia del "matasellos", timbres que se estampan para indicar desde dónde es remitida la carta o paquete y el día de envío, esto con la finalidad de que se sepan estos datos y de que el sello no sea reutilizado. Ello adquiere un especial valor para la filatelia, que privilegia la colección de estampillas mataselladas por sobre las "mint”, es 
decir, aquellos sellos postales sin utilizar y que se encuentran con su goma original (Fredes, 2000).

Considerando los elementos anteriores, más allá de la filatelia - entendida como la colección, clasificación y sistematización de sellos postales- durante las últimas décadas se han publicado importantes obras que utilizan a las estampillas como fuente principial, destacándose el libro de Jack Child (2008) "Miniature Messages: the semiotics and politics of Latin American Postage Stamps", la colección “Autorretratos del Estado" (2013 y 2015) dirigida por el Dr. Guillermo Navarro para el caso de España que aborda la Historia de España desde 1850 hasta 2014 en tres volúmenes, hasta el texto de Rozas y Terré (2017) "Los mensajes filatélicos contra la violencia hacia las mujeres", por mencionar algunos.

Por otra parte, el sello postal corresponde a aquellos soportes de arte que se observan cotidianamente en el día a día: “...como la arquitectura, iconografía de billetes, monedas y estampillas..." (Errázuriz y Leiva, 2012: 8), y, por ende, tienen la posibilidad de generar propaganda a nivel masivo: “...la inclusión de imágenes en su diseño demuestra que el sello de correo desempeña otra función aparte de certificar que se han pagado los costes del envío. Si fuera de otra manera, con un simple indicativo bastaría... Por tanto, los productos culturales elegidos para ocupar el lugar de honor de los sellos también hablan de los objetivos y la ideología de un estado" (Navarro y Senís, 2012: 256-257). De allí que el carácter propagandístico de las estampillas sea eficaz, dado que:
El sello no es una táctica estética espectacular en tamaño, pero sí en eficacia. Es un goteo continuo que erosiona la percepción del receptor de correo hasta crear dentro de su imaginario particular un hueco donde se encierra una serie de imágenes y de referencias estéticas en el más amplio sentido de la palabra, y, sobre todo, artísticas y literarias. A través, pues, de los sellos, el Estado se asegura, debido a su control absoluto sobre su emisión, la consolidación de ciertos mitos artísticos que son aceptados como tales en tanto en cuanto es el propio Estado el que los legitima mediante su inclusión en un documento de valor oficial (Navarro y Senís, 2012: 257).

Por ende, la fuente principal de este trabajo son los sellos postales: instrumentos emanados del Estado, representante de los gobiernos en ejercicio del poder en un contexto en que la circulación de estampillas, durante la segunda mitad del siglo $\mathrm{XX}$, fue de gran importancia. Considerando lo anterior, la pregunta que origina la investigación es: ¿Cómo el gobierno de turno construyó y reflejó la representación de los roles femeninos a través de los sellos postales emitidos en Chile entre 1964 y 1995? Por ende, la hipótesis propuesta es que, en los sellos postales emitidos en Chile entre 1964 - 1995, las representaciones y roles asignados a las mujeres se vincularon a roles tradicionales como el de madre y pilar de la familia, donde, además, la influencia católica se hace presente a través de la imagen de ejemplos de virtud como la Virgen María, santas y beatas. Esto se produce durante todo el período, independiente de la ideología del gobierno de turno. Considerando 
lo anteriormente planteado, el objetivo general es indagar en los roles de género asignados a las mujeres en representaciones y textos de los sellos postales emitidos en Chile entre 1964 y 1995. En concordancia, los objetivos específicos son: catastrar los sellos postales emitidos en Chile en el período señalado que hagan alusión a la mujer, así como ejemplificar los principales tópicos relacionados con roles de género asociados a lo femenino en los sellos postales del período temporal indicado.

En cuanto al marco temporal escogido, este se fundamenta en que la etapa 1964 - 1990 es una época de importantes cambios a nivel nacional, desde la: "“revolución en libertad", "revolución socialista con sabor a empanadas y vino tinto" (Rojas, 1997: 378), donde la primera corresponde al gobierno de Frei Montalva (1964-1970) y la segunda al de Salvador Allende (1970-1973). Dichos gobiernos fueron los últimos del período de "Estado de compromiso" (Ossa, 2017), el que se extiende entre 1925 y 1973, que se caracterizó por la importante presencia del Estado en diversos ámbitos de la vida como la economía y se discutió acerca de políticas controversiales como la Reforma Agraria. Dichas discusiones se vieron reflejadas en los sellos postales de la época, donde se evidencian estas políticas que cada gobierno impulsó y visibilizó, como la ya mencionada Reforma Agraria, Nacionalización del Cobre, Planificación Familiar, entre otras. En tanto, el período de la dictadura cívico militar (1973-1990) se caracterizó por: “[...] la lógica totalizadora del golpe de Estado como por la redefinición política que supuso..." (Ossa, 2017: 21), lo que se reflejó a su vez en los medios de comunicación de masas, los que: “...se vieron afectados por una serie de medidas, tales como cierres, confiscaciones, represiones y censuras, las cuales tenían por objeto la desmovilización y despolitización del país” (Rivera, 2017: 233). Como es evidente, la lógica dictatorial se reflejó también en las estampillas a través de las distintas emisiones conmemorativas del Golpe de Estado y figuras políticas del siglo XIX donde la figura de Diego Portales es protagonista, el realce del rol de las Fuerzas Armadas, entre otras.

El regreso a la democracia no estaría exento de dificultades, dado que: “[...] el interés por la política había disminuido y los temas que eran considerados problemas nacionales fueron desplazados por los "intereses de la gente"” (Rivera, 2017: 211). No obstante, entre los primeros sellos postales emitidos el 8 de junio de 1990 por el gobierno de Patricio Aylwin (1990-1994) se enviaron mensajes que llamaron a la unidad a través de consignas como: "Un Chile para todos los chilenos" (1990) y conmemoraron la Democracia con mensajes de "Paz en Chile", "Amanece en Chile", en los que no se observa la representación del género femenino. El corte temporal de la investigación se relaciona con la emisión de la primera serie de estampillas dedicadas a conmemorar el día internacional de la mujer, las que fueron patrocinadas por PRODEMU (Fundación para la Promoción y Desarrollo de la Mujer), emitidas el 8 de marzo de 1995, a días del primer aniversario de la presidencia de Eduardo Frei Montalva.

Se escogió trabajar con una temática de género dado que a pesar de que durante las últimas décadas ha aumentado la producción intelectual en esta línea, las investigaciones enfocadas en los roles de las mujeres tienden a considerarse: 
“[...] en general y con pocas excepciones, como una "historia adicional, hecha solo por mujeres para mujeres, entendida en clave subalterna respecto a la jerarquía de la mainstream history" (Stabili, 2017: 244, cursiva del texto original). A lo anterior, se suman los giros de la política de la época estudiada, que, según Alfaro, Inostroza y Hiner (2021) llevaron a que, tras la consecución del derecho a voto, se produjera una fragmentación del movimiento feminista, lo que provocó una distancia entre las transformaciones sociales de la época y la representación política, donde: “...los "verdaderos" hombres -y mujeres- de la revolución tenían que ser heterosexuales y cisgénero" (Alfaro, Inostroza y Hiner, 2021: 66), y por ende, se mantuvo el carácter conservador propio de la cultura burguesa, donde la crianza de las/os hijas/os era asignado principalmente a las mujeres (Alfaro, Inostroza y Hiner, 2021: 67). Consideramos como base la definición de género dada por ONU mujeres (2016), la que señala:

El género se refiere a los roles, comportamientos, actividades, y atributos que una sociedad determinada en una época determinada considera apropiados para hombres y mujeres. Estos atributos, oportunidades y relaciones son construidos socialmente y aprendidos a través del proceso de socialización. Son especificas al contexto/época y son cambiantes. El género determina qué se espera, qué se permite y qué se valora en una mujer o en un hombre en un contexto determinado (ONU mujeres, 2016: 43).

Como fuente principal fueron utilizados sellos postales mint, así como tarjetas del primer día de emisión sin matasellado, para poder visualizar directamente las imágenes que se presentaron en cada sello postal. Estas han sido extraídas de la colección personal de la autora, así como del catálogo disponible en la página Chile Collector (https://www.chilecollector.com/index.html), asociada a la sociedad filatélica del país.

Es importante señalar que el estudio metodológicamente es de carácter cualitativo, entendiendo a este como la utilización de textos, imágenes y otras fuentes, ya que “...parte de la noción de la construcción social de las sociedades sometidas a estudio" (Flick, 2007: 20); esto, contrario a lo que se planteaba tradicionalmente en relación con una supuesta carencia de dimensión social en el análisis de iconografías como fuente principal de un estudio en el área de las ciencias sociales (Burke, 2005). Esto, no impidió la utilización de algunas referencias numéricas generales, con el afán de contextualizar los sellos referidos a nuestro tema de estudio. Por otra parte, el estudio es exploratorio, dado que no existen investigaciones que utilicen esta fuente para indagar en roles de género utilizando como fuente los sellos postales chilenos. En cuanto al muestreo, este se enmarca en los métodos visuales propuestos por Flick (2007), por lo que fue realizado en base al contexto de producción de las imágenes, es decir: considera los sellos postales emitidos en Chile entre 1964 y 1995 en los que aparezcan imágenes de mujeres, o se haga alusión a ellas en el texto de la estampilla. Es importante señalar que el artículo presenta características monográficas, ya que se centra en los roles de género asignados a las mujeres por el Estado, el discurso y la visualidad reflejada en los sellos postales, lo que en palabras de Child no 
constituye un estudio filatélico ni de aficionados, sino que académico y analítico (Child, 2008). Para finalizar este apartado, es necesario considerar el enfoque deductivo del artículo, dado que se ha partido exponiendo algunas consideraciones generales en esta introducción, a continuación se desarrolló un breve estado del arte del sello postal como fuente histórica, para proceder a exponer, posteriormente, los resultados generales del catastro de estampillas, así como se ejemplifica en seis imágenes algunos de los tópicos más recurrentes de los roles asignados a la mujer en el período señalado.

\section{Los sellos postales: su utilización como fuente histórica}

Una parte importante de los estudios realizados en Chile hasta el momento han abordado los sellos postales como un trabajo de catálogo, patrimonio gráfico y transmisor cultural complementario a las crónicas históricas, como tarea de un coleccionista, un documento visual que otorga simple testimonio de una época, sin una identidad visual propia.

Un primer trabajo a considerar es el libro de César Hidalgo Calvo (1986), Teoría y Práctica de la Propaganda Contemporánea, el que califica a las estampillas como medio propagandístico secundario, ya que estas: “...son otro buen vehículo de recordación de nombres o slogans ... pueden tener una alta difusión o conductividad al quedar adheridas en los más diversos lugares" (Hidalgo, 1986: 169-170); tras lo que se avoca a resaltar la importancia de la propaganda postal, la que al hacer referencia al envío de cartas con fines político-propagandísticos, sale de nuestro objeto de estudio. No obstante, reconoce que: "En ocasiones, hasta el diseño o el contenido simbológico (sic) de los sellos postales constituye un medio de transporte válido del mensaje implícito en ellos" (Hidalgo, 1986: 181). En la misma línea está el trabajo de Luis Reyes, quien señala: “Nos parece, en definitiva, que este se presenta como un trabajo complementario..., que puede, reiteramos, enriquecer tanto nuestro concepto del pasado, como nuestro método de y trabajo para su estudio" (Reyes, 2012: 169-170).

Por otra parte, Errázuriz (2009), considera los sellos postales como una herramienta de transmisión cultural, en los que ha quedado marcada la ideología de los distintos gobiernos de Chile, con especial énfasis en la dictadura cívico militar. En la misma línea, Errázuriz y Leiva (2012) plantearon que las estampillas son creadas para influir en el imaginario colectivo, dado que: "proyectan una imagen de país al exterior, puesto que su destino trasciende muchas veces las fronteras, cada vez más abiertas... la presencia de un objeto tan pequeño de representaciones de identidad nacional al alcance un vasto sector de la población permitiría una especie de apropiación afectiva con el significado de ese objeto" (Errázuriz y Leiva, 2012: 77). De allí que en este estudio se ejemplifiquen algunos de los sellos postales significativos de las políticas públicas y de las ideologías del gobierno de Allende y Dictadura cívico- militar. No obstante, el análisis es general (solo abarca de las páginas 76 a la 92, donde gran parte de estas están dedicadas a la reproducción de imágenes), por lo que no profundiza en una catalogación 
más profunda dado que no es el objetivo de la investigación.

En elámbito del diseño, destaca el trabajo de Muñoz (2006), en el que se señala que los sellos postales chilenos constituyen: “...una manifestación visual de nuestra identidad... -que se convier ten- en un importante transmisor de patrimonio cultural..." (Muñoz, 2006:125). En esta línea, la autora señalada indica de qué manera impactó el inicio de la globalización sobre la cultura, el patrimonio y las estampillas, para describir el proceso de selección temática, producción y emisión de los sellos de la época, así como la emisión de catálogos. Finalmente, analiza algunas piezas de diseño y producción de estampillas.

En el ámbito del coleccionismo, la Sociedad Filatélica de Chile cuenta con la publicación en formato digital de la revista "Chile Filatélico" desde el número 1 (marzo de 1929) hasta el 300 (noviembre 2019-abril 2020) Los números señalados se encuentran disponibles en la página web: https://www.sociedadfilatelica.cl/chilefilatelico. php

Como quedó en evidencia, en este breve estado del arte de los trabajos que han utilizado los sellos postales como fuente, no existe alguno que se haya dedicado a realizar una aproximación con perspectiva de género. De todas maneras, es importante señalar que por motivos relacionados con el contexto actual (cierre de bibliotecas) no fue posible incorporar a la investigación el texto de Jaime Soto (1993) “El arte en los sellos postales de Chile".
A nivel internacional, uno de los estudios más importantes es el de Child (2008), el que aborda los sellos postales desde una perspectiva semiótica y política, enfocándose en las estampillas emitidas en América Latina con énfasis en América del Sur, especialmente en Argentina, país de origen del autor. Child, entrega importantes elementos a considerar al momento de utilizar las estampillas como fuente, como por ejemplo el que su dimensión en miniatura implica el que: "Para hacer más fuerte y efectivo la declaración visual contenida en esta pequeña área bidimensional, el diseñador utilizar un color, tipografía y símbolos de contraste para entregar un mensaje visual efectivo" (Child, 2008: 35). De allí la importancia de cada elemento que considera el sello postal en su configuración, dado que todos los elementos que lo componen tienen algún significado en él.

Otro de los estudios destacados es la colección dirigida por Navarro (2015). Esta, consta de tres volúmenes en los que analiza cómo la historia de España contemporánea (desde el reinado de Isabel II hasta la transición a la democracia. Basada en la tesis doctoral del autor, los tomos entregan información pertinente no solo para el país en que se desarrolla el estudio, sino que aportan al estudio general de los sellos postales desde perspectivas teóricas y ejemplos concretos. Uno de los puntos importantes que explicita el autor tiene que ver con que:

Los sellos postales solo muestran imágenes favorables del Estado emisor, especialmente cuando se representa la historia, pues no hay menciones a genocidios, atrocidades o derrotas. Otro tanto ocurre con la representación 
de la industria o el turismo, actividades estas de las que solo se muestra la cara amable obviando, por ejemplo, la contaminación o diversos tipos de turismos éticamente reprobables cuando no directamente ilegales" (Navarro, 2015: 14-15).

Esto es claramente aplicable a los sellos postales chilenos, sobre todo en un período de cambio social como el estudiado. Durante los gobiernos de Frei, Allende ni durante la dictadura cívico-militar no se visibilizan las movilizaciones sociales, las violaciones a los Derechos Humanos ni los procesos de privatización de entidades estatales. En cambio, sí se destacan leyes acordes a la ideología de cada gobierno (como la Reforma Agraria con un sello emitido en 1968 durante el gobierno de Frei o la nacionalización del cobre en otro sello de 1972, en el caso de Allende), el auge de las exportaciones (como una serie de estampillas dedicadas a la comercialización de frutas con el extranjero en 1989) durante la dictadura, así como, el retorno a la democracia en 1990. Es importante señalar que en solo uno de los sellos postales mencionados se visualiza una mujer (en el primero de ellos). Por otra parte, el mismo estudio de Navarro (2015) contiene al menos un capítulo dedicado al rol atribuido a la mujer, específicamente durante el Franquismo, texto que fue escrito por Pelta (2015) y que aporta al mostrar cómo se idealizó a la mujer en roles tradicionales como el de enfermera, profesora y madre; donde la máxima expresión de esta última instancia es la visualización del culto mariano.
Hoyo (2014), aporta a los estudios basados en sellos postales desde la perspectiva del "imaginario nacional oficial", el que:

permite la constitución, la continuación y la legitimidad de una comunidad nacional al establecer tres aspectos esenciales de ella: primero, los requisitos que toda persona, objeto o lugar debe poseer para ser considerado como parte de la nación; segundo, los elementos comunes que se consideran como los fundantes del grupo en términos históricos, sociales e institucionales; tercero, los elementos diferenciadores que, cuando menos en teoría, hacen a dicha comunidad esencialmente diferente del resto de las naciones y grupos en el mundo (Hoyo, 2014: 173).

Para el autor, la importancia de utilizar los sellos postales como fuente para el estudio de dicho imaginario, tiene que ver con su doble dimensión: nacional e internacional, dado que, a diferencia de monedas y billetes, estos llegan a la población interna del país que lo emite, así como a la externa, a través del envío de cartas, postales y paquetes. De allí la cualidad de poder representar a nivel masivo mundial los principios bajo los cuales se construye una comunidad imaginada (Hoyo, 2014: 177).

Por otra parte, y vinculado a temáticas de género, encontramos el estudio de Rozas y Terré (2017), el que se aborda la violencia contra la mujer como un problema de salud pública, el que ha sido visibilizado y puede ser concientizado a nivel social a través de los mensajes que se incluyen en los sellos postales que circulan en los distintos continentes. 
Las autoras realizan un rastreo general de dichas estampillas, así como una catalogación general que da cuenta de la visibilización del problema, donde se destacan como tópicos la violencia doméstica, la lucha por los derechos de la mujer, la mutilación genital y la agresión sexual ejercida contra las mujeres. Las autoras establecen que existe un lenguaje iconológico específico para algunas de estas categorías, lo que facilita su interpretación en el contexto social e internacional en el que se difunden. En Chile, no se cuenta con sellos postales específicos que den cuenta de estas problemáticas, lo que puede constituir una herramienta a considerar por trabajar por parte de correos.

Si bien existen otros estudios susceptibles de mencionar (como Bushnell, 1997; Scott, 1995, por mencionar algunos), se optó por especificar las investigaciones ya desarrolladas, dado que no es el objetivo de este artículo el realizar un estado del arte pormenorizado; pero sí lo expuesto es pertinente al momento de reafirmar la validez de la fuente utilizada, así como la versatilidad que esta tiene para difundir y reafirmar los lazos nacionales (Hoyo, 2014), hasta el poder concientizar a la población acerca de problemáticas globales.

\section{Una aproximación a la imagen de la mujer a través de los sellos postales chilenos (1964-1995)}

Como se planteó en el primer objetivo específico, se realizó un catastro general de sellos postales emitidos en Chile en el período a estudiar. En él, se diferenciaron tres categorías generales:
Sellos postales con figuras masculinas o textos que hicieran alusión a lo masculino: abarca desde los "padres de la patria" (Bernardo O`Higgins, José Miguel Carrera), figuras religiosas (Juan Pablo II, Gandhi), oficios tradicionales (pescadores, chinchineros), militares, entre otros. Es importante señalar que, si aparecía la imagen de una mujer junto a la de los hombres, se consideró dicha imagen como sello con figura femenina. Esto ocurrió principalmente en representaciones de santos (como San Vicente de Paul, emitida en 1981) y de familia (como la emitida en 1967 de la VIII Conferencia internacional de planificación de la familia).

Sellos postales con figuras de mujeres o textos que hicieran alusión a lo femenino: considera iconografías de religiosas (Virgen María, santas y beatas, nacimiento de Jesús), mujeres de los pueblos originarios, por ejemplificar.

Otros motivos: incorpora una amplia gama de temáticas, las que van desde reivindicaciones territoriales sobre la Antártica, como la emitida en 1972 y analizada en Child, 2008, además de otra emitida en 1989; exportaciones de frutas (emitidas en 1973, 1989, vr. gr.); flora y fauna del país (emitidas en 1987, 1988, 1991, 1992); medios de transporte como barcos y aviones, tanto militares como civiles, y trenes (emitidas en 1983, 1987, 1990, 1991,1992, 1993, entre otras), Iglesias (como la colección emitida en 1993, que es trabajada brevemente por Muñoz, 2006), por mencionar algunas temáticas. 
Lo primero que se puede observar es el bajo número de estampillas que utilizan figuras femeninas o hacen referencias a mujeres en sus textos, como muestra la siguiente tabla:

Tabla 1: Catastro general de sellos postales emitidos en Chile, 1964-1995

\begin{tabular}{|l|l|l|l|l|}
\hline Año & $\begin{array}{l}\mathrm{N}^{\circ} \text { total de sellos } \\
\text { emitidos }\end{array}$ & $\begin{array}{l}\mathrm{N}^{\circ} \text { de sellos con figura o } \\
\text { texto masculino }\end{array}$ & $\begin{array}{l}\mathrm{N}^{\circ} \text { de sellos con figura } \\
\text { o texto femenino }\end{array}$ & $\begin{array}{l}\mathrm{N}^{\circ} \text { de sellos con otros } \\
\text { motivos }\end{array}$ \\
\hline $1964-1995$ & 779 & 215 & 90 & 475 \\
\hline
\end{tabular}

Fuente: elaboración propia en base a catálogo Chile Collector.

Lo anterior, implica que solo un $11,4 \%$ de las estampillas emitidas en el período señalado, referencian a alguna imagen femenina o la mencionan en algún texto. De hecho, hay años donde no se encuentra ninguna iconografía de mujer, como por ejemplo en 1964, 1969, 1973. Hay otros años donde solo se encuentra un sello: 1965, 1966, 1967, 1970, 1976 y 1990. Llamativo resulta este último dato, dado que es el con una mayor cantidad de sellos emitidos del período (77 en total), donde se refleja la finalización de la dictadura cívico - militar y el retorno a la democracia, lo que se produce a través de emisiones postales como el inicio de la serie que homenajea a los presidentes de Chile electos del siglo XX (desde 1925 hasta 1973), y donde se realzan los llamados a la paz, alegría y armonía con la colección "Democracia en Chile". No obstante, las mujeres no se encuentran representadas ni visibilizadas en los sellos postales de ese año clave para el país más que para Navidad, imagen donde aparecen un niño y una niña armando un árbol de Pascua. Esto, a pesar del documento "Las demandas de las mujeres en democracia" de 1988. Como señalan Alfaro, Inostroza y Hinner (2021: 89-90): “...las reivindicaciones contenidas en este documento se postergaron y se elaboraron en clave "medida de lo posible", a partir de una Programa para la Mujer implementado en los primeros años de la postdictadura...".

Además de lo anterior, se suman otras estampillas en los que las mujeres se ven excluidas de manera reiterada, como lo que sucede con el caso de los homenajes a las Fuerzas Armadas que se emiten durante la dictadura cívico-militar. Ejemplo de ello es lo que sucede en 1974, con una serie de cinco estampillas: en la primera aparece la figura de O'Higgins acompañado de los escudos de las cuatro ramas, mientras que en las siguientes se dedica un sello a la Armada, Carabineros, Fuerza Aérea y Ejército. En cada una aparece la imagen de un soldado realizando una actividad afín a la rama a la que pertenece (un hombre piloteando un avión, por ejemplo), donde la ausencia de la representación del personal femenino es evidente. 
Tabla 2. Las mujeres en los sellos postales chilenos (1964-1995): clasificación temática

\begin{tabular}{|c|c|c|c|c|c|c|c|c|}
\hline $\begin{array}{l}\text { Virgen María, } \\
\text { s a n t a s y } \\
\text { beatas }\end{array}$ & Otros & $\begin{array}{l}\text { Madre,familia, } \\
\text { rol doméstico }\end{array}$ & $\begin{array}{l}\text { Estudiante y } \\
\text { niñez }\end{array}$ & $\begin{array}{l}\mathrm{P} \text { u e b l o s } \\
\text { originarios }\end{array}$ & $\begin{array}{l}\text { Gabriela } \\
\text { Mistral }\end{array}$ & Deportes & $\begin{array}{l}\text { Enfermera, } \\
\text { cuidadora }\end{array}$ & $\begin{array}{l}\text { Javiera } \\
\text { Carrera }\end{array}$ \\
\hline 29 & 27 & 8 & 7 & 5 & 5 & 4 & 3 & 2 \\
\hline
\end{tabular}

Fuente: elaboración propia en base a catálogo Chile Collector.

De las 90 estampillas del período en la que aparecen mujeres o se hace referencia a ellas, se realizó una clasificación de los roles y contextos en los que estas aparecen. Las categorías son:

Virgen María, santas y beatas: corresponde a la utilización de iconografías y mensajes vinculados a conmemoraciones como el "Voto Nacional O’Higgins - Maipú” (1970), donde aparece la Virgen del Carmen a propósito de la conmemoración del voto de O’Higgins a dicha representación mariana de 1818; la celebración de la Navidad, la beatificación (1989) y canonización (1993) de Teresa de Los Andes, por mencionar algunas.

Otros: engloba diversas instancias como la visita de la Reina Isabel II a Chile en 1968; la representación de mujeres en pinturas que se refleja en cinco sellos postales de los años 1975 y 1991, la conmemoración del 8 de marzo en el año 1995.

Madre, familia, rol doméstico: se observa la presencia de la mujer en contextos vinculados a la maternidad y la construcción de un grupo familiar en sellos que resaltan la planificación familiar (1967), el año internacional de la vivienda (1987), por ejemplo. En algunos casos, aparecerá con un bebé en brazos (1972, 1975), mientras que en otras se resaltará su rol doméstico social en instituciones como CEMA Chile (Centros de Madre), en años como 1977.

Estudiante y niñez: en esta categoría se reunieron los sellos en los que aparecen niños en distintas instancias, tales como la labor de protección al menor, donde las/os menores aparecen realizando una ronda (estampilla emitida para el cuarto aniversario del Golpe de Estado), o en contextos escolares, como es el caso de la imagen de una estudiante escribiendo en una pizarra a propósito del aniversario del Consejo Interamericano Cultural de la Organización de los Estados Americanos, CIECC (1978).

Pueblos originarios: si bien, son pocas las menciones a los pueblos originarios, resulta llamativo el que la mayoría de las mujeres representadas sean de la Isla de Pascua (1986, 1988, 1992).

Gabriela Mistral: es la segunda representación más importante en cuanto a las veces que aparece en los sellos postales, después 
de la Virgen María. En este caso, se le relaciona con cuestiones educacionales, como una campaña de alfabetización (1966) o se conmemora el centenario de su nacimiento, recatando los hitos más importantes de su vida.

Deportes: tales como la participación en eventos deportivos con cuatro sellos postales, como el campeonato nacional de ski de 1966.

Enfermera, cuidadora: ya sea como acompañante de un menor con síndrome de Down (sello del año 1981, en el que aparece la leyenda: "al niño limitado, amor ilimitado") o como enfermera conmemorando los 125 años de la Cruz Roja y Media Luna Roja.

Javiera Carrera: es la única mujer que aparece como destacada y asociada a un rol político. Aparece en 1981 para el bicentenario de su nacimiento, así como en 1994 para los 300 años del liceo de niñas que lleva su nombre.

Al realizar el ejercicio de clasificación, resulta evidente la preeminencia de las imágenes religiosas asociadas a la mujer, con un $32,5 \%$. De estas 29 estampillas, seis son imágenes de la Virgen María (Virgen del Carmen, emitida en 1970; Virgen del cerro, emitida en 1971, por ejemplo), mientras que 19 corresponden a la celebración de la Navidad, por lo que en este caso, la presencia de la mujer (Virgen María) resalta su rol de madre en el pesebre. De hecho, desde que comenzó la emisión de estos sellos postales en 1977 y que anualmente visualizan el 25 de diciembre como una festividad importante, lo que se mantiene hasta la actualidad; no siempre ha implicado una garantía de que se incorpore en la iconografía la representación de una mujer o de la Virgen, como sucedió en 1975, donde se muestra a un ángel o en 1985 donde aparece un bebé en un pesebre.

Imagen 1: Navidad 1993

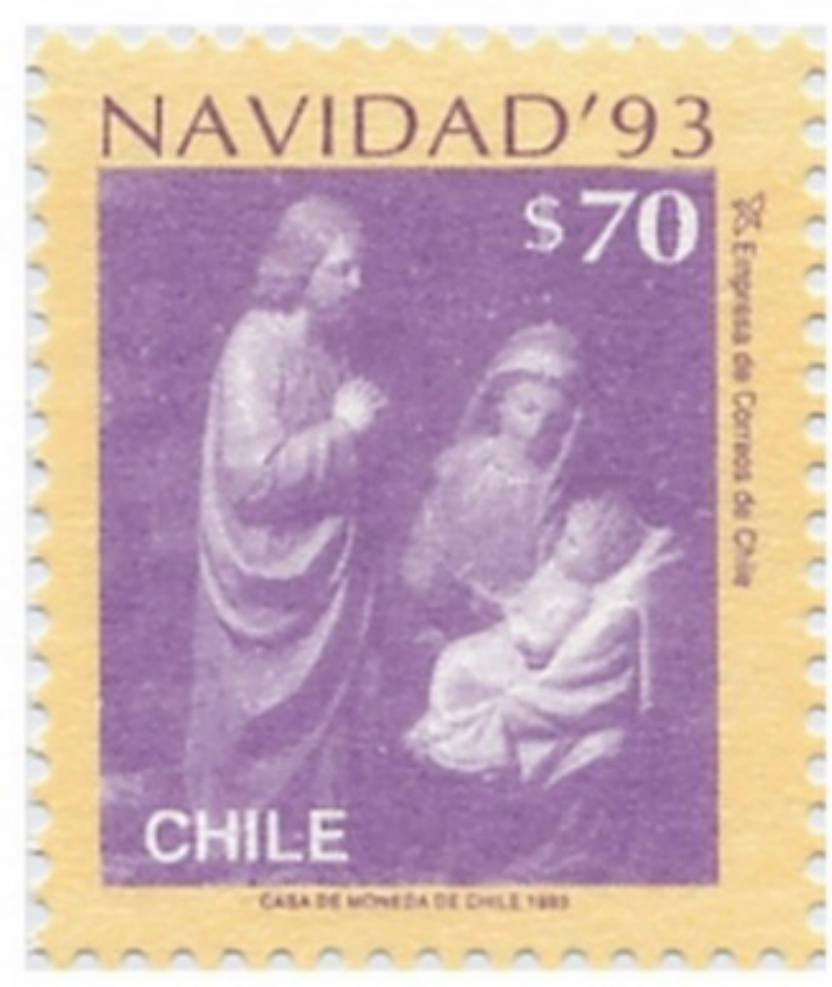

Fuente: colección personal.

Fue emitido en 1993, durante el gobierno de Patricio Aylwin (1990-1994), quien fue militante de la Democracia Cristiana y el primer presidente tras el inicio del proceso de transición a la democracia. No obstante, este sello postal forma parte de una serie de estampillas que correos de Chile emite anualmente para conmemorar la Navidad, por lo que la temática que aborda no se relaciona con el gobierno de turno. 
Como se observa en la imagen 1, y de acuerdo con lo señalado con anterioridad, la imagen de la Virgen aparece en un segundo plano, dado que el protagonista de la composición es Jesús como bebé recién nacido. A ello se suma el que María aparece supeditada a su rol de madre, como sucede en la mayoría se los sellos postales donde aparece. Esto, no fue únicamente un fenómeno que se produjera en Chile, dado que, como explica Pelta (2015) para el caso español:

No resulta extraño que la mayor parte de los sellos postales con la mujer como protagonista estén dedicados a la maternidad y que la gran mayoría de ellos, además, sean de temática religiosa, con la Virgen como modelo y siguiendo una iconografía que encaja perfectamente con la exaltación de valores como la castidad y la virginidad que solo pueden ser abandonados por la necesidad de ser madre (Pelta, 2015: 115).

Como se ha señalado con anterioridad, la preeminencia de este tipo de imágenes se contradice con el rol público y político que la mujer jugó durante el período estudiado, ya que como señala Stabili (2017: 268), se produjo una: “...dicotomía entre esfera pública y privada que... fue utilizada para justificar la exclusión de la mujer del ejercicio público del poder", la que no impidió que las mujeres lucharan para ser sujetos de derecho en distintos ámbitos como el político, económico y jurídico.

Es importante señalar que, en la línea de la cultura católica, no solo se emitían estampillas vinculadas al nacimiento para Navidad, sino que también se pueden encontrar sellos postales referidos a santas y beatas: Santa Rosa de Lima (1986), Laura Vicuña (1989), así como los dos sellos ya mencionados que resaltan la figura de Teresa de los Andes, por mencionar algunas.

Imagen 2: Campaña nacional de alfabetización (1966)

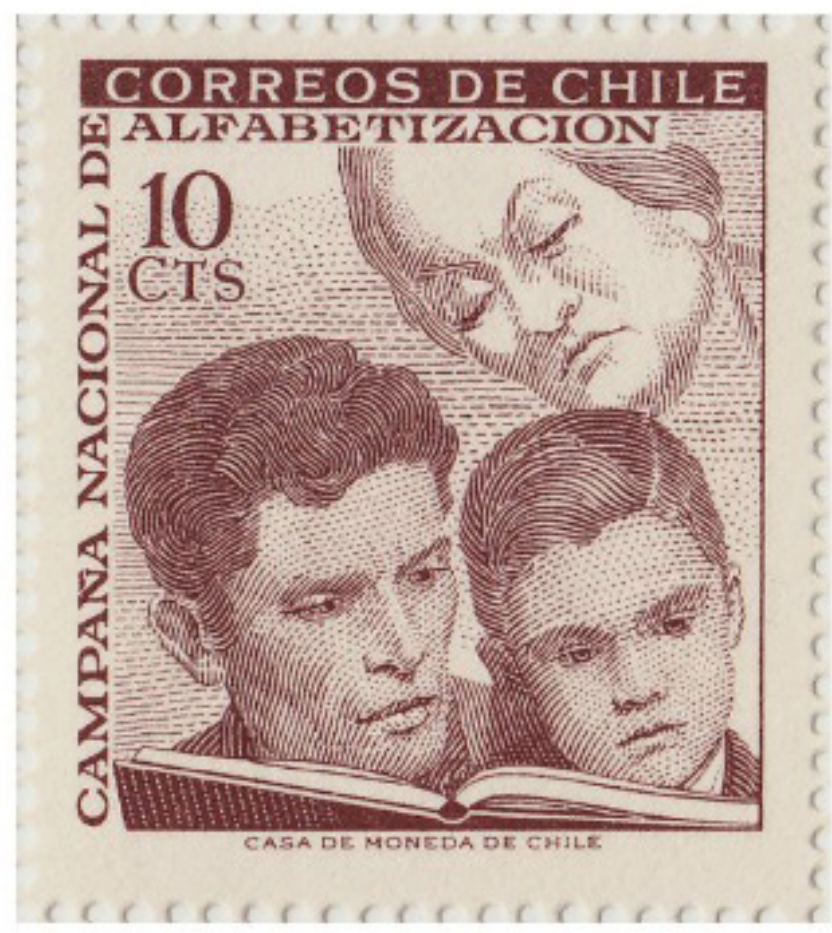

Fuente: colección personal.

Como fue señalado anteriormente, la imagen de Gabriela Mistral corresponde a la segunda representación femenina más recurrente del período estudiado -después de la Virgen María- con un total de cinco sellos postales. En el caso del sello presentado, la poetiza chilena aparece en segundo término tras la representación de dos varones que están leyendo.

El contexto de emisión es de la reforma educacional (1965) impulsada durante el gobierno del 
democratacristiano Eduardo Frei Montalva, la que tuvo uno de sus sustentos el estudio "Bases generales para el planeamiento de law educación chilena" (1961), en el que se dejó constancia de que para la época el analfabetismo total afectaba a $\mathbf{1 7 0 . 0 0 0}$ personas. La reforma educacional, encabezada por el ministro Juan Gómez Millas, diferenció a los niveles educacionales parvulario, básico y medio; donde el estadio básico de ocho años de duración pasa a ser de carácter obligatorio. De allí la importancia de recalcar la alfabetización como una tarea fundamental para Chile, en la que la figura de la maestra de escuela Gabriela Mistral era inspiradora. Resulta importante este contexto, dado que, en la mayoría de los sellos postales emitidos en el período, Gabriela Mistral aparece vinculada al rol docente, salvo uno emitido en 1995 a propósito de la conmemoración de la obtención del premio Nobel de Literatura.

En la línea de lo ya planteado, observamos como la figura femenina aparece, en los sellos postales emitidos por el Estado chileno entre 1964 y 1995, sujeta nuevamente a un rol tradicional, en este caso el de educadora.
Imagen 3: Dueños de nuestro propio destino (1972)

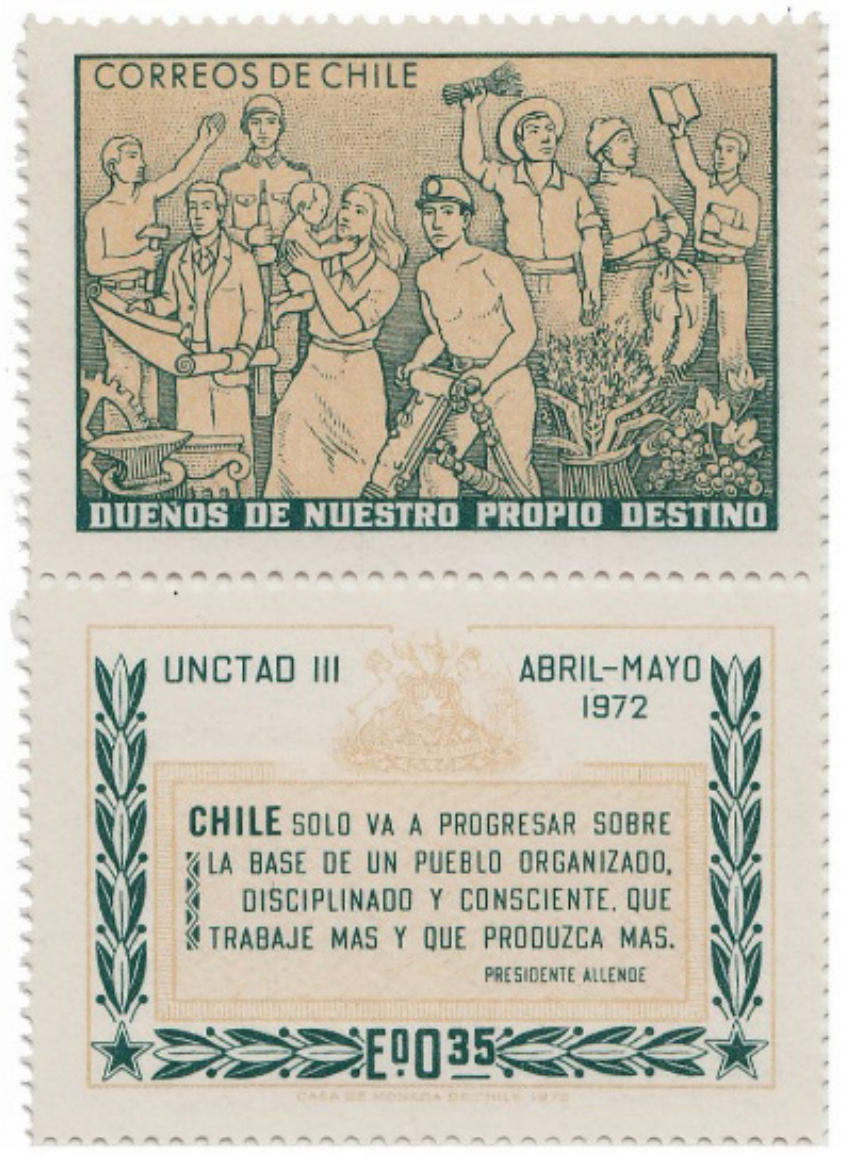

Fuente: colección personal.

La estampilla presentada fue emitida durante el gobierno de Salvador Allende. Específicamente, conmemora la inauguración de la III Conferencia delas Naciones Unidas sobre Comercio y Desarrollo en el Tercer Mundo (UNCTAD III), la que fue posible gracias a la rápida construcción del edificio que actualmente corresponde al GAM, que según el portal Memoria Chilena, demoró solo 275 días en ser levantado. De allí se comprende el extracto del discurso de Allende, que recalca el rol de los trabajadores en un contexto de cambio social. 
Esimportante señalar que, si bien se observan dos piezas postales, estas constituyen un solo sello, dado que solo una cuenta con el valor de venta $\left(0,35 \mathrm{E}^{\mathrm{o}}\right)$. Este sello postal ha sido referenciado en otras obras como en Errázuriz, Leiva (2012:78), en la que se rescata el carácter político que refleja la estampilla, lo que queda evidenciado no solo en las imágenes de trabajadores, sino que en la cita explícita de un extracto del discurso del presidente Salvador Allende; donde, además:

La frase "Dueños de nuestro propio destino" se deja sentir como el esolgan (sic) de una campaña sostenida de reivindicación de la autonomía política, es decir, contra el “imperialismo", que es algo que estaba presente en casi todos los discursos del presidente Allende (Errázuriz, Leiva, 2012:79).

No obstante, lo anterior, la única mujer que aparece en el sello lo hace desde su rol de madre con un bebé en brazos, mientras los hombres son representados en funciones laborales y productivas que incluyen desde un minero hasta un militar, pero ninguno aparece como padre o vinculado a labores domésticas o de crianza.

Ello, a pesar de la activa participación política de las mujeres en la época que se ejemplifica en los cordones industriales del área textil (Salgado, 2019). Sin embargo, el rol presentado en el sello postal es coherente con lo planteado por Alfaro, Inostroza y Hinner (2021: 69), en cuanto:

Los activismos de las mujeres y sus discursos, en el proceso de construcción de un proyecto global como el de la UP, se encontraban diferenciados por el lugar que ellas ocupaban en torno a las jerarquías de género y de clase... Es a partir de ello que las tensiones entre poder y la política de las mujeres se van a expresar principalmente en este momento en las distintas militancias políticas y sociales.

Por ende, no resulta extraño encontrar que un discurso político que resalte la independencia y el aporte que cada ciudadana/o realizaba al país, se de a la mujer en un rol propio de la cultura patriarcal de la época. Con la dictadura militar se resalta nuevamente una imagen de la mujer recatada y de madre, como podemos observar a continuación.

Imagen 4: Block Souvenir homenaje al año internacional de la mujer (1975)

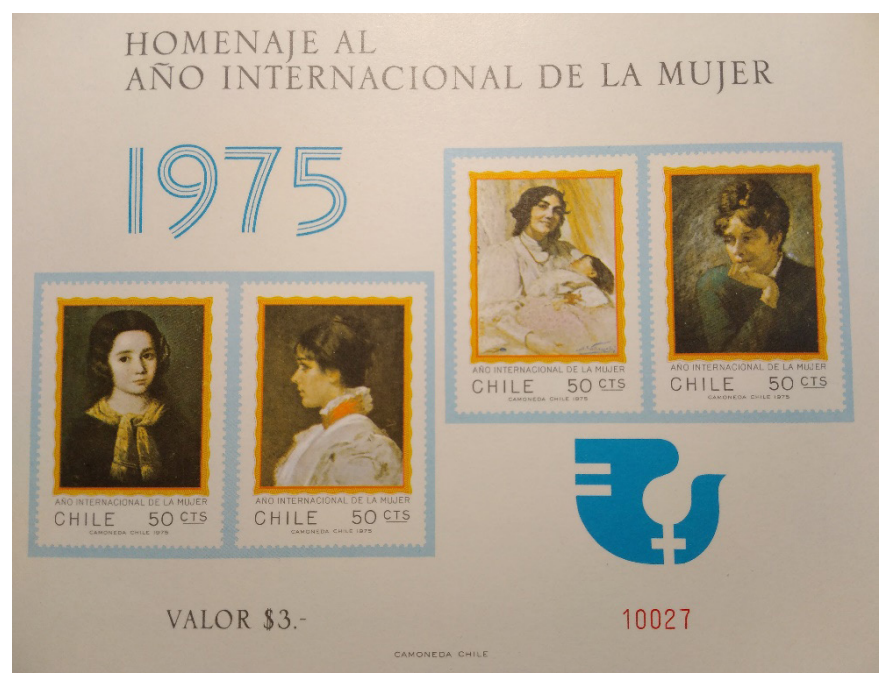

Fuente: colección personal.

En el block presentado, que contiene una serie de cuatro estampillas emitidas por Correos de 
Chile en 1975, se observan, de izquierda a derecha, pinturas de Francisco Mandiola, Pedro Lira, Alfredo Valenzuela y Magdalena Mira. Solo una de las obras fue realizada por una mujer. Es importante resaltar la tercera pintura, titulada: "La mamá feliz", que corresponde a una de las últimas creaciones de Valenzuela (MINEDUC, 1985:50), en la que se observa a una mujer con un bebé en brazos. Vemos como nuevamente se remite a la maternidad como algo intrínsecamente ligado a lo femenino y como un rol social que es susceptible de ser homenajeado.

Imagen 5: Chile, un país para soñar (1986)

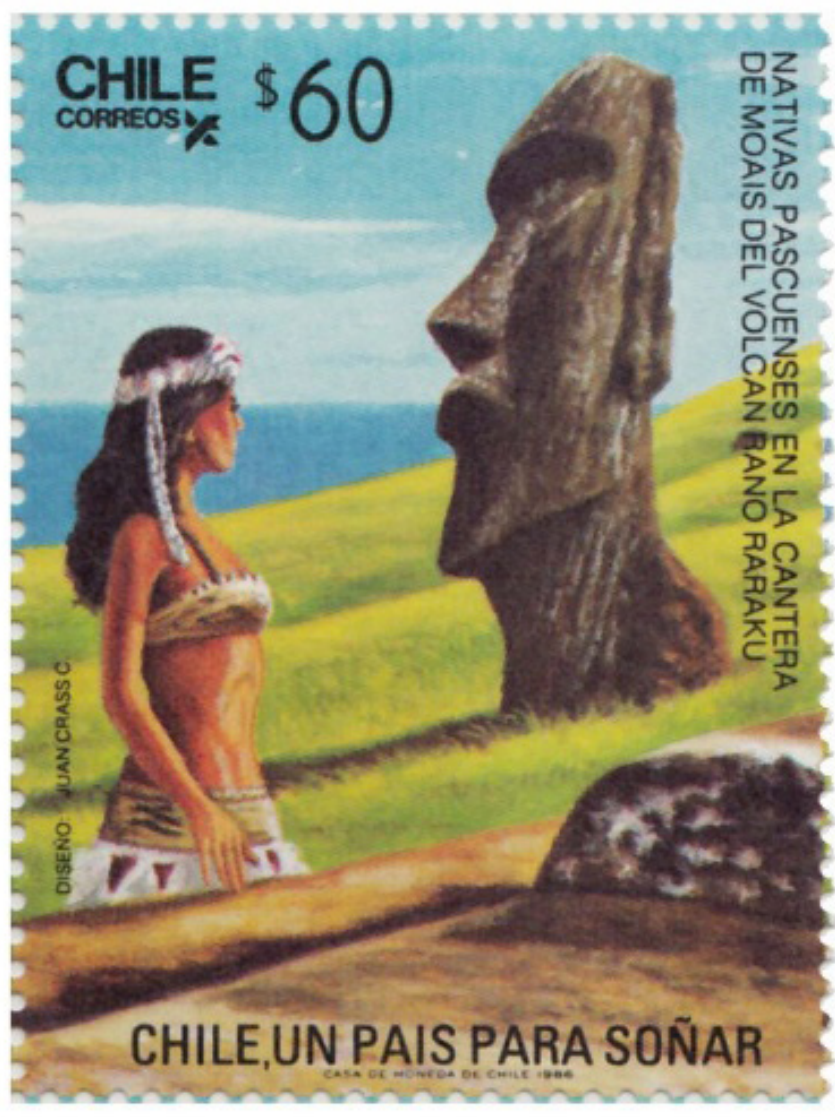

Fuente: colección personal.
Este sello es parte de una emisión compuesta por dos sellos: el de la imagen número cuatro, y otro donde aparece un hombre junto a un Moai. Estos junto a otros sellos temáticos de flora y fauna (1984, 1987, 1988, 1991, 1993, por ejemplo), artesanías nacionales (1991) y personajes típicos (1985), buscan rescatar y mostrar el patrimonio del país. En palabras de Muñoz (2006):

A través de sus temáticas los sellos postales difunden la diversidad cultural de nuestro país, al expresarla la sociedad se vuelve más consciente de su existencia, y, por lo tanto, se lucha contra su desaparición, el patrimonio cultural, se representa de diferentes maneras en los sellos postales, reconociéndose y entregándole valor por medio de su difusión. Así el patrimonio cultural de nuestro país queda registrado para ser mostrado a las nuevas generaciones (Muñoz, 2006: 177).

Por otra parte, también muestra parte de la cultura y de la etnia Rapa Nui. Al observar a la mujer representada, esta cumple con el canon estético occidental al lucir un abdomen plano y resaltar atributos de carácter sexual como senos y cintura. Esto, se ve complementado por la emisión en 1988 de una serie de cuatro estampillas para conmemorar el centenario de la anexión de la Isla de Pascua a Chile, donde aparecen Policarpo Toro, una proyección de la isla sobre el mundo, otra con petroglifos y una donde aparece un hombre de pie rodeado de cuatro mujeres arrodilladas ante él. En la última estampilla mencionada así como en la presentada los roles de género están definidos con la predominancia del hombre y la postura/ sexualización de las mujeres. Esto, es concordante 
con lo planteado por Bruel (2008), quien señala que los modelos/estereotipos de género:

En función de sus características sexuales externas y de las distintas funciones dentro del proceso reproductivo se asignaron a varones y mujeres una serie de roles diferenciales en pro de la vida en sociedad... Estos modelos definen la vida de las personas a través de una normativa que apunta los derechos y deberes, prohibiciones y privilegios que cada uno tiene por pertenecer a uno u otro sexo. Puede haber una variación del contenido en función del contexto étnico, religioso y socioeconómico; sin embargo, se observa con frecuencia en casi todas las culturas el hecho de que el modelo de masculinidad es más valorado y goza de mayor prestigio social que el modelo asignado a las mujeres (Bruel, 2008: 71 y 73).

No ocurre lo mismo con la representación de otras etnias del país como la mapuche, lo que probablemente se relacione con que a través de los sellos postales también se promocionaban lugares que visitar para fomentar el turismo, donde la de Isla de Pascua aparece como un destino atrayente y exótico.
Imagen 6: Día internacional de la mujer (1995)

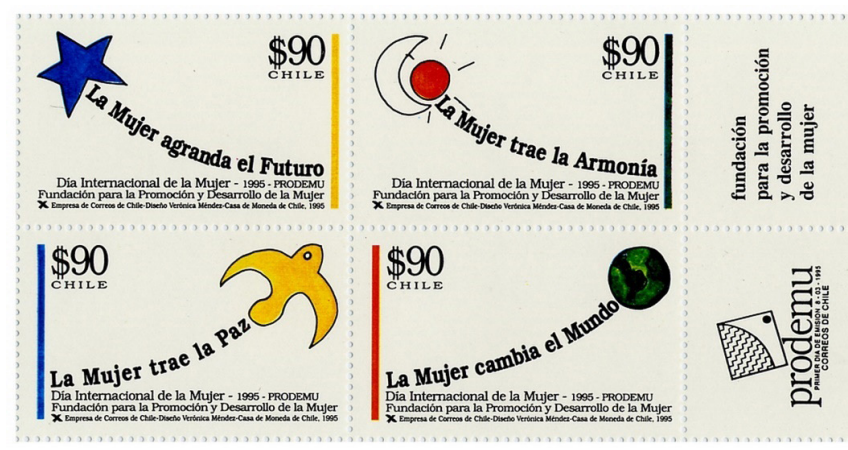

Fuente: colección personal.

La última imagen presentada, corresponde a la primera conmemoración del 8 de marzo como Día Internacional de la mujer, a través de sellos postales chilenos. La emisión está compuesta por cuatro estampillas, cuya publicación fue solicitada por PRODEMU (Fundación para la Promoción y el Desarrollo de la Mujer). De acuerdo con lo explicado por Muñoz (2006), la publicación de un sello postal con temáticas específicas como el presentado, es un proceso que demora al menos un año y que pasa por la aprobación de la Gerencia General de Correos y el Directorio de la misma entidad.

Como se puede observar, la composición gráfica de los sellos consta de una línea en el margen izquierdo, el valor en el costado superior izquierdo, una frase asociada a atribuciones de la mujer, que son aplicables alámbito doméstico y social, tales como la misión de traer armonía, pazy cambiar el mundo. Con todo, resulta un avance importante el que se haya visualizado la conmemoración del 8 de marzo en 1995. De hecho, este es el único sello postal que encontramos que ha sido emitido en 
Chile que se refiera a esta importante fecha, lo que fue posible gracias a lo que Hinner y López (2021) denominan como feministas institucionalizadas, es decir: “...mujeres profesionales y universitarias que se hacen parte de las políticas impulsadas por los gobiernos concertacionistas, integrándose al Sernam (sic) y otras instituciones, impulsando Organizaciones No Gubernamentales (ONG), centros de estudio y fundaciones..." (Hinner, López, 2021: 97). Sin la labor realizada por quienes integraron el PRODEMU de la época e intentaron "cambiar el mundo", como reza uno de los sellos postales, no tendríamos este testimonio visual que rompe con la tradición de mujer vinculada a la maternidad, la familia y a la cristiandad, por mencionar algunos de los tópicos más reiterativos de acuerdo con el catastro realizado para este estudio.

\section{Conclusiones preliminares}

En el presente estudio se planteó como hipótesis el que en los sellos postales emitidos en Chile entre 1964 - 1995, las representaciones y roles asignados a las mujeres se vincularon a roles tradicionales como el de madre y pilar de la familia, donde, además, la influencia católica se hace presente a través de la imagen de ejemplos de virtud como la Virgen María, santas y beatas. Como se pudo visualizar a través del catastro realizado, del total de 779 estampillas emitidas en el período, en 90 sellos aparecían imágenes o textos vinculados a mujeres, de la cuáles las principales iconografías representadas se relacionan con la figura de la Virgen María, santas y beatas, con 29 estampillas. Esto nos muestra la preeminencia de la cultura católica tradicional en la sociedad, donde el segundo ícono femenino con mayor representación es Gabriela Mistral (5 sellos postales), destacada por su rol de educadora, seguida de Javiera Carrera (con 2 estampillas).

No obstante, un hallazgo importante lo constituyen los silencios u omisiones que encontramos en años como 1973 o 1990, donde se pudo rescatar que los sellos postales emitidos por los gobiernos de Chile omiten el rol político que la mujer cumplió en períodos y años de profunda transformación social, independiente de la ideología de cada gobierno. Al momento de trabajar con una herramienta como la estampilla que construye nación (Hoyo, 2014) y representa la imagen del país ante la comunidad interna e internacional (Child, 2008; Navarro, 2015), es evidente que estas ausencias imponían un modelo de rol de la mujer en una sociedad dominada por hombres, en la que las mujeres aún se encontraban luchando por sus derechos políticos.

Entre las posibles proyecciones del trabajo, encontramos elementos como la realización de un rescate patrimonial, la evolución monetaria del país, entre otros. No obstante, aún queda mucho por hacer y visibilizar en cuanto a quebrar la visión tradicionalista de la mujer en los sellos postales chilenos, pudiendo abordar temáticas como la prevención de la violencia contra la mujer (Rozas y Terré, 2017), mujeres pioneras en Chile en distintas áreas, en la línea de lo trabajado por la arquitecta Paulina Montero en su Instagram @nosedefilatelia en 2019, entre otros elementos. 


\section{Referencias citadas}

Alfaro K., Inostroza G. y Hiner H. (2021): "El poder de desafiar el poder. Movimiento de mujeres y feministas en la revolución contra la dictadura (1950-1990)", en Históricas: movimientos feministas y de mujeres en Chile, 1850-2020. Santiago, LOM, p.p. 57-90.

Asain F. (2017): Herramienta de simulación para evaluación de rendimiento de cuarteles de Correos de Chile. Tesis de Magíster en Gestión de Operaciones, Memoria para Optar al Título de Ingeniero Civil Industrial. Universidad de Chile, Santiago de Chile.

Bruel T. (2008): Representaciones sociales de género: Un estudio psicosocial acerca de lo masculino y lo femenino. Tesis de Doctorado en Psicología. Universidad Autónoma de Madrid, Madrid.

Burke P. (2005): Visto y no visto, Barcelona, Crítica.

Child J. (2008): Miniature Messages. The semiotics and politics of Latin American Postage Stamps, Duke University Press.

Errázuriz L. (2009): “Dictadura militar en Chile. Antecedentes del golpe estético", Latin American Research Review, 44 (2), pp. 136-157.

Errázuriz L y Leiva G. (2012): El golpe estético. Dictadura militar en Chile (1973-1989), Santiago, Ocho Libros.

Flick U. (2007): El diseño de investigación cualitativa, Madrid, Morata.

Hidalgo C. (1986): Teoría y Práctica de la Propaganda Contemporánea, Santiago, Editorial Andrés Bello.
Fredes C. (2000): Filatelia y región, Santiago, Cuadernos del Bío-Bío.

Hinner H. y López A. (2021): “Movimientos feministas y LGTBQ+: de la transición pactada a la revuelta social, 1990-2020, en Históricas: movimientos feministas y de mujeres en Chile, 1850-2020, Santiago, LOM, pp. 91-127.

Hoyo H. (2014): “ ¿Juntos y bien revueltos? La representación etnocultural de México en estampillas postales de 1930-1940", en Schuster, S. La nación expuesta: cultura visual y procesos de formación de la nación en América, México, Editorial Universidad del Rosario, pp. 173- 198.

Jaksic I. y Ossa J. (2017): Historia política de Chile, 18102010. Tomo I: Prácticas políticas, Santiago, FCE-UAI.

MINEDUC (1961): Bases generales para el planeamiento de la educación chilena. Santiago: Escuela Nacional de Artes Gráficas. Recuperado de: http://www.memoriachilena.gob.cl/602/w3-article-64077.html [Consulta: 22 de mayo de 2021]

MINEDUC (1985): Panorama de la pintura chilena: Los pintores de medio siglo en Chile, tomo II, Santiago, Departamento de Extensión Cultural del Ministerio de Educación.

Muñoz, J. (2006): “El sello en Chile: rescate y valorización de los sellos postales nacionales como transmisores del patrimonio cultural y como patrimonio gráfico de Chile", en Concurso Nacional Tesis Bicentenario, Comisión Bicentenario, Santiago de Chile, 2006, pp. 123-253.

Navarro G. y Senís J. (2012): “Mitos dentados: el sello 
postal como factor constructor del imaginario cultural durante el franquismo", en Arnabat R. y Gavaldá A., Projectes nacionals, identitats irelacions Catalunya-Espanya, Catarroja, Afers, pp. 253-264.

Navarro G. (2015): Autorretratos del Estado. II. El sello postal del franquismo, España, Ediciones de la Universidad Castilla La Mancha, Editorial Universidad de Cantabria.

ONU Mujeres (2016): Profundizando en términos de género. Guía de terminología, uso de lenguaje no sexista para periodistas, comunicadoras y comunicadores, ONU Mujeres, Guatemala.

Ossa J. (2017): “Introducción”, en Jaksic I. y Ossa J. Historia política de Chile, 18010-2010. Tomo I, prácticas políticas, Santiago, FCE- UAI.

Pelta R. (2015): “O santa o nada”. La imagen de la mujer en el sello postal del franquismo, en: Navarro G. Autorretratos del Estado. II. El sello postal del franquismo, España, Ediciones de la Universidad Castilla La Mancha, Editorial Universidad de Cantabria.

Reyes L. (2012): "Hacia el futuro en libertad. Conmemoraciones postales del Golpe de Estado en Chile", Nuestra Historia, 5 (5), pp. 165-208.

Rivera C. (2017): "Prensa política. El poder de la construcción de la realidad. Chile, siglos XIX y XX", en Jaksic I. y Ossa J. Historia política de Chile, 180102010. Tomo I, prácticas políticas, Santiago, FCE- UAI.

Rojas F. (1997): “Chile: cambio político e inserción internacional 1964-1997", 432 Estudios internacionales, 30(119-120), pp. 376-406.
Rozas M. y Terré C. (2017): “Los mensajes filatélicos contra la violencia hacia las mujeres", Musas, 2(2), pp. 3 - 27. DOI: 10.1344/musas2017.vol2.num2.1

Salgado X. (2019): “Organización Política y Sociabilidad Popular: Cordón Industrial Cerrillos-Maipú y el paro de octubre de 1972”, en Grupo de estudios Germinal, Se levanta el clamor popular. Experiencias del pueblo organizado durante el gobierno de los mil días 1970-1973, Santiago, FECH.

Stabili M. (2017): “La Res-Pública de las mujeres”, en Jaksic I. y Ossa, J. Historia política de Chile, 180102010. Tomo I, prácticas políticas, Santiago, FCE- UAI.

VV.AA (s/f): Inauguración UNCTAD III. Recuperado de: http://www.memoriachilena.gob.cl/602/w3-article-128020.html [Consulta: 23 de mayo de 2021] 